\title{
Effects of Therapeutic Riding in Children with Spastic Cerebral Palsy
}

\author{
Ok-Deuk Kang ${ }^{1 *}$, Wang-Shik $\mathrm{Lee}^{2}$ and Yu-Jeong $\mathrm{Ko}^{3}$ \\ ${ }^{1}$ Department of Hippotherapy, Sung Duk University, Young Chun, Gyeongbuk, Korea, ${ }^{2}$ Division of Biotechnology, Jeju \\ National University, Jeju 690-756, Korea, ${ }^{3}$ Department of Occupational Therapy, Kunjang College, Goonsan, Korea
}

\begin{abstract}
This study examined the effect of therapeutic horseback riding in children with spastic cerebral palsy. Participants were placed in a therapeutic riding (TR) group $(\mathrm{n}=7)$ or physical therapy (PT) group $(\mathrm{n}=7)$. This study was then conducted for 30 minutes, twice a week, for 8 weeks. The gross motor function measure (GMFM), range of motion (ROM), and spasticity test (ST) were analyzed pre-test (TR0 and PT0), mid-test (TR1 and PT1), and post-test(TR2 and PT2). We used the SPSS 12.0 statistical software for data analysis. We observed significant changes in GMFM Dimension C (crawling and kneeling), D (standing), and E (walking, running, and jumping) between TR2 and TR0 $(P<0.05)$. In the control group, GMFM Dimension B (sitting) and E showed significant changes between PT2 compared to PT0 $(P<0.05)$. In future studies we will consider using a therapeutic riding program for the treatment of children with disorders.
\end{abstract}

(Key words : Cerebral palsy, Horseback riding, Equine assisted therapy, Physical therapy)

\section{INTRODUCTION}

The introduction of sports therapy may have a significant impact on accelerating the rehabilitation of children with cerebral palsy $(\mathrm{CP})$.

$\mathrm{CP}$ is an umbrella term that encompasses a group of non-progressive, non-contagious motor conditions that cause physical disability in human development, chiefly in the various areas of body movement (Nelson \& Russman, 2002). It is a chronic condition that often requires lifelong participation in physical and occupational therapy (Ionatamishvili, 2004). CP patients are typically unable to maintain a right posture and balance because they have trouble with controlling their head and stabilizing their trunk. In addition, CP patients have imbalanced muscles due to muscular weaknesses and muscle atrophy from muscle stiffness. Therefore, to promote functional independence and minimize disability in the daily activities of $\mathrm{CP}$ patients, systematic and continuous strengthening of physical motor abilities must be encouraged (Sherri et al., 2002; Dodd et al., 2003).

To aid the walking ability of CP patients, improvements in trunk balancing ability to relieve spasticity are especially critical and there are a variety of therapies to strengthen trunk muscles (Kim, 2005). Horseback-riding for the disabled is a form of sports intervention therapy widely used to promote posture stability and stimulate a sense of balance in CP patients (Liptak, 2005).

Since 1969, after the establishment of the Riding for the Disabled Association(RDA), many countries, including the U.S., have widely used horseback riding for the disabled. Numerous studies have proven the effects of riding for the disabled. An overall improvement of gross motor function after 18 weeks of horseback riding was observed (Strerba et al., 2002). In addition, significant improvements in balance after 7 weeks of horseback riding (Silkwood-Sherer, 2007) and increased range of motion after 18 weeks of horseback riding (Bergene, 2006) were reported.

Riding for the disabled is currently used in Korea for children with $\mathrm{CP}$, and its effectiveness has gradually been proven (Kim et al., 2005; Yong et al., 2010; Kwon et al., 2011). Children with CP improved their gross motor function after horseback riding for 10 weeks (Kim et al., 2005)). In addition, 8-weeks of horseback riding treatment helped CP patients improve their gross motor function as well as balance in children (Kwon et al., 2011). Another study (Yong et al., 2010) also reported that 5-months of horseback riding therapy helped improve gross motor function. However, it is difficult to carry out riding for children with $\mathrm{CP}$ since it involves a living animal and several other obstacles, such as

* Corresponding author: Ok-Deuk Kang, Department of Hippotherapy, Sung Duk University, Young Chun, Gyeongbuk, Korea. Tel: +82-54-330-8714, Fax: +82-54-330-8896, E-mail: kod0816@nate.com 
a lack of experts and horses.

Due to these obstacles, research studies on the effects of riding for the disabled are rare. Therefore, this study aimed to confirm the effectiveness of riding for children with $\mathrm{CP}$ through a 6-month horseback riding exercise program to improve their sense of balance.

\section{MATERIALS AND METHODS}

\section{Participants}

Fourteen children diagnosed with $\mathrm{CP}$ participated in the study at the Jeju Horse Land in Jeju City on Jeju Island (Table 1). All participants were recruited from the Ever Spring Rehabilitation Hospital in Jeju City on Jeju Island, South Korea. Participants received the riding program at no cost after they agreed to participate and their parents signed the consent forms. Participants included the therapeutic riding (TR) group $(n=7)$ and physical therapy (PT) group $(n=7)$ (Table 1). The TR and PT groups were each comprised of four children with diplegia and three children with hemiplegia. All participants received continued physical therapy before, during, and after the project, except the TR group did not receive physical therapy during the horse riding period.

\section{Horses}

The horses used were three clinically healthy female Jeju crossbred riding horses, $14.5 \pm 0.7 \mathrm{yrs}$ of age, weight 322.5 $\pm 3.5 \mathrm{~kg}$, withers heights $128.0 \pm 1.7 \mathrm{~cm}$, and chest width 67.5 $\pm 0.7 \mathrm{~cm}$. According to the official manual for the Riding for the Disabled Association (RDA), a good behavior, including a calm and good temperament, is essential for equine-assisted therapy. If the horse's temperament is suitable, the horse's body type becomes an important selection criterion.

Matsuura et al. (Matsuura, 2008) stated that the body type of a horse affects a rider's movement and a shorter horse provides rider stability and is helpful to side-walkers as well. The Jeju cross bred horse is relatively short (approximately $135 \mathrm{~cm}$ height) and features a wide chest width therefore, it was selected for this project.

\section{Experimental design}

This study protocol was approved by the Ethics Committee for Human Research (Approval NO. 2012-14) of Jeju National University in South Korea. An experiment design model was used to determine the effects of the therapeutic riding program (Fig. 1). The participants were divided into two groups, a therapeutic riding (TR) group and a physical therapy (PT) group. The TR program was provided from a registered instructor in the Professional Association of Therapeutic Horsemanship International (PATH Intl.). Horses and participants were appropriately matched, depending on size, through the same instructor. All participants wore helmets for safety. Volunteers were used, where one led the horse and two were side walkers.

The 16 sessions given to the TR group were conducted given by a certified instructor in PATH. The PT group received physical therapy by physical therapists for 16 sessions in the hospital. Toanalyze the participants' abilities, the GMFM, ROM, and ST were analyzed before TR (TR0 and PT0), after 8 sessions of TR(TR1 and PT1), and after 16 sessions of TR (TR2 and PT2).

\section{Measurements}

TR was conducted for 30 minutes, twice a week, for 8 weeks. Each measurement was performed three times at the

Table 1. Physical characteristics of children by age and gender

\begin{tabular}{|c|c|c|c|c|c|c|}
\hline \multirow{2}{*}{ Participant } & \multicolumn{3}{|c|}{ Treatment } & \multicolumn{3}{|c|}{ Control } \\
\hline & Age & Gender & Type of CP & Age & Gender & Type of CP \\
\hline 1 & 4 & M & Diplegia & 5 & $\mathrm{~F}$ & Diplegia \\
\hline 2 & 6 & M & Diplegia & 4 & M & Diplegia \\
\hline 3 & 7 & M & Diplegia & 7 & M & Diplegia \\
\hline 4 & 9 & M & Diplegia & 12 & M & Diplegia \\
\hline 5 & 5 & $\mathrm{~F}$ & Hemiplegia (Rt.) & 5 & M & Hemiplegia (Rt.) \\
\hline 6 & 10 & M & Hemiplegia (Lt.) & 7 & M & Hemiplegia (Lt.) \\
\hline 7 & 14 & $\mathrm{M}$ & Hemiplegia (Rt.) & 9 & M & Hemiplegia (Lt.) \\
\hline
\end{tabular}




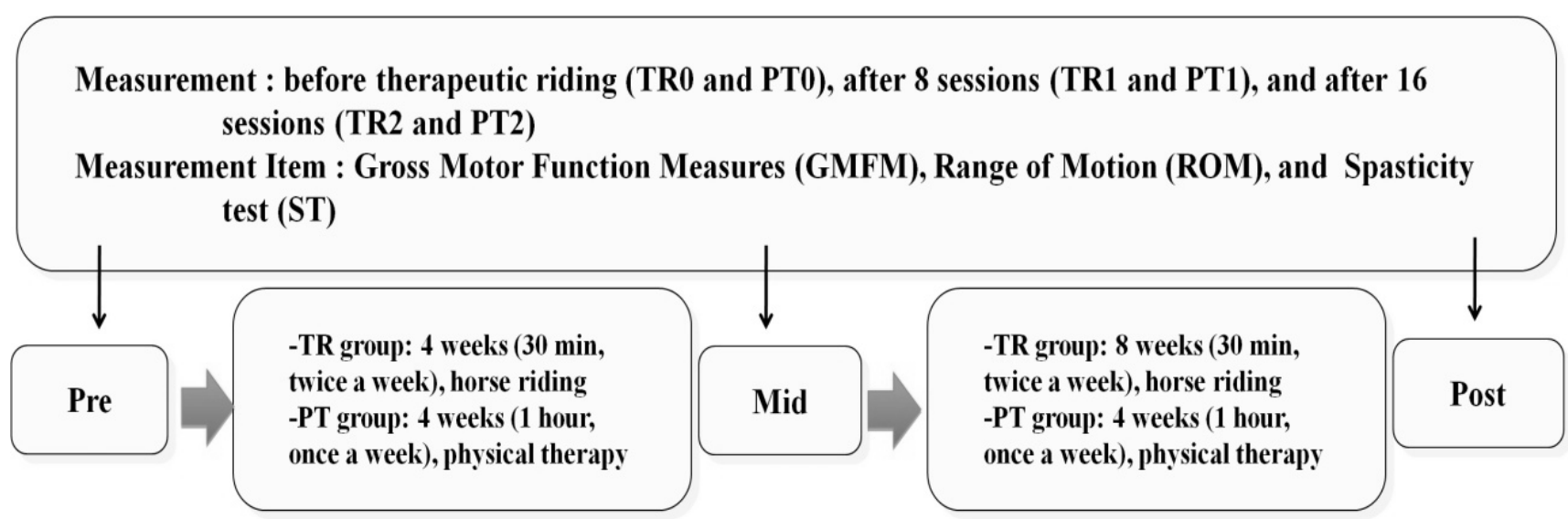

Fig. 1. Experimental design.

pre-test and post-test. All measurements of the participants were conducted by the same occupational therapist and physical therapists at the Ever Spring Rehabilitation Hospital.

\section{(1) Gross Motor Function Measures (GMFM)}

The GMFM has been demonstrated to have high levels of validity, reliability, and responsiveness in assessing motor function and the effects of physical therapy in children with CP (Russel et al., 1989; Bjornson et al., 1998). Therefore, the GMFM was chosen to measure clinical changes in TR participants (Sterba et al., 2002). The GMFM consists of 88 items organized into five dimensions: (A) lying and rolling, (B) sitting, (C) crawling and kneeling, (D) standing, and (E) walking, running, and jumping. The total GMFM score was derived through averaging the percent scores for all five dimensions (A through $\mathrm{E}$ ) in accordance with the GMFM training manual (Russell et al., 1993).

\section{(2) Range of Motion (ROM) and Spasticity Test (ST)}

Range of motion (ROM) reflects the flexibility of joints, or how much movement occurs at a joint. A goniometer (a protractor with two, extended, moveable arms) was used to determine the range of motion and measure the angles of joints to measure musculoskeletal and joint flexibility (Baine, 1965). In this study, the range of motion of each joint and the spasticity test were used to assess the rider at the pre-test, mid-test, and post-test.

\section{Statistical analysis}

SPSS 12.0 statistical software was used for data analysis. Nonparametric statistical tests were utilized due to the small sample size. Friedman's Two-Way ANOVA was used to calculate the pre-test, mid-test, and post-test within group scores. All statistical analyses were calculated using alpha levels of $\mathrm{p}<0.05$.

\section{RESULTS AND DISCUSSION}

Means and standard deviations of total score (\%) were recorded for all subscales for the pre-test and post-test for the therapeutic riding and physical therapy groups (Table 2).

Changes in GMFM scores of TR and PT groups according to test period were recorded (Table 3). Individual results describing changes in the individual total GMFM scores (\%) of the TR and PT groups were also determined (Fig. 2). In the TR group, GMFM increased at a rate of $2 \%$ to $25 \%$, GMFM in the PT group increased at a rate of $0 \%$ to $17 \%$ (Fig. 2). Although there were differences between individuals, the result indicates that both the TR group and PT group tended to exhibit increases in GMFM (Fig. 2).

The experimental group was significantly different in GMFM Dimension C (crawling and kneeling), D (standing), and E (walking, running, and jumping) between TR2 and TR0 (Table 3). However, no significant differences were observed in Dimension A and B during therapeutic riding. In the PT group, GMFM Dimension B (sitting), D (standing), and $\mathrm{E}$ (walking, running, and jumping) were significantly different between PT2 and PT0 $(\mathrm{P}<0.05)$ (Table 3). ROM and ST showed no differences in range of motion and spasticity between the experimental and control groups.

Horseback riding therapy has long been known as a beneficial form of treatment for patients with a variety of disorders (Baine, 1965; Russell et al., 1993). In this therapy, 
Table 2. Changes in GMFM scores between groups

\begin{tabular}{|c|c|c|c|c|}
\hline \multirow{2}{*}{ Dimension } & \multirow{2}{*}{ Time } & TR & PT & \multirow{2}{*}{ Significance } \\
\hline & & Mean \pm SD & Mean \pm SD & \\
\hline \multirow{3}{*}{ A: Lying and Rolling } & Pre & $95.7 \pm 7.3$ & $99.4^{\mathrm{a}} \pm 1.5$ & .424 \\
\hline & Mid & $99.4 \pm 1.5$ & $100.0^{\mathrm{a}} \pm 0.0$ & .317 \\
\hline & Post & $99.7 \pm 0.8$ & $100.0^{\mathrm{a}} \pm 0.0$ & .317 \\
\hline \multirow{3}{*}{ B: Sitting } & Pre & $97.9 \pm 3.7$ & $98.7^{\mathrm{a}} \pm 0.8$ & .588 \\
\hline & Mid & $98.7 \pm 0.8$ & $99.0^{\mathrm{a}} \pm 1.3$ & .708 \\
\hline & Post & $99.0 \pm 2.6$ & $99.6^{\mathrm{a}} \pm 1.1$ & .917 \\
\hline \multirow{3}{*}{ C: Crawling and Kneeling } & Pre & $83.0 \pm 13.4$ & $88.1^{\mathrm{a}} \pm 8.3$ & .797 \\
\hline & Mid & $88.1 \pm 8.3$ & $86.9^{\mathrm{a}} \pm 8.6$ & .747 \\
\hline & Post & $89.9 \pm 8.1$ & $91.9^{\mathrm{a}} \pm 5.0$ & .517 \\
\hline \multirow{3}{*}{ D: Standing } & Pre & $67.3 \pm 31.6$ & $81.4^{\mathrm{a}} \pm 29.8$ & .336 \\
\hline & Mid & $81.4 \pm 29.8$ & $65.4^{\mathrm{a}} \pm 19.8$ & $.024^{*}$ \\
\hline & Post & $88.3 \pm 17.2$ & $69.7^{b} \pm 23.6$ & $.025^{*}$ \\
\hline \multirow{3}{*}{ E: Walking, Running, and Jumping } & Pre & $55.0 \pm 34.8$ & $65.6^{\mathrm{a}} \pm 33.3$ & .655 \\
\hline & Mid & $65.6 \pm 33.3$ & $51.9^{\mathrm{a}} \pm 13.0$ & .225 \\
\hline & Post & $71.6 \pm 28.9$ & $64.1^{\mathrm{b}} \pm 21.0$ & .250 \\
\hline
\end{tabular}

Levels of significance: ${ }^{*} \mathrm{p}<0.05$.

Table 3. Changes in GMFM scores according to period in children in TR and PT groups

\begin{tabular}{|c|c|c|c|c|}
\hline \multirow{2}{*}{ Dimension } & Pre-test & Mid-test & Post-test & \multirow{2}{*}{$P$} \\
\hline & Mean \pm SD & Mean \pm SD & Mean \pm SD & \\
\hline \multicolumn{5}{|l|}{ Treatment group } \\
\hline A: Lying and Rolling & $95.7 \pm 7.3$ & $99.4 \pm 1.5$ & $99.7 \pm 0.8$ & NS \\
\hline B: Sitting & $97.9 \pm 3.7$ & $98.7 \pm 0.8$ & $99.0 \pm 2.6$ & NS \\
\hline C: Crawling and Kneeling & $83.0^{\mathrm{a}} \pm 13.4$ & $88.1^{\mathrm{a}} \pm 8.3$ & $89.9^{\mathrm{b}} \pm 8.1$ & $*$ \\
\hline D: Standing & $67.3^{\mathrm{a}} \pm 31.6$ & $81.4^{\mathrm{a}} \pm 29.8$ & $88.3^{\mathrm{b}} \pm 17.2$ & * \\
\hline E: Walking, Running, and Jumping & $55.0^{\mathrm{a}} \pm 34.8$ & $65.6^{\mathrm{a}} \pm 33.3$ & $71.6^{\mathrm{b}} \pm 28.9$ & $*$ \\
\hline \multicolumn{5}{|l|}{ Control group } \\
\hline A: Lying and Rolling & $99.7 \pm 0.8$ & $100.0 \pm 0.0$ & $100.0 \pm 0.0$ & NS \\
\hline B: Sitting & $98.3 \pm 1.3$ & $99.0 \pm 1.3$ & $99.6 \pm 1.1$ & NS \\
\hline C: Crawling and Kneeling & $85.6 \pm 7.0$ & $86.9 \pm 8.6$ & $91.9 \pm 5.0$ & NS \\
\hline D: Standing & $62.1^{\mathrm{a}} \pm 24.4$ & $65.4^{\mathrm{a}} \pm 19.8$ & $69.7^{\mathrm{b}} \pm 23.6$ & $*$ \\
\hline E: Walking, Running, and Jumping & $44.4^{\mathrm{a}} \pm 21.2$ & $51.9^{\mathrm{a}} \pm 13.0$ & $64.1^{\mathrm{b}} \pm 21.0$ & $*$ \\
\hline
\end{tabular}

Levels of significance: ${ }^{*} \mathrm{p}<0.05$.

a rider takes in the sensory input conveyed by the soft and rhythmical movement of a horse (Spink, 1993). Therefore, many previous studies focused on horse riding for the disabled and examined how a rider can improve the effects derived from the movements of the horse. In these techniques, the rider did not directly control the horse but instead used a soft blanket (no saddle and stirrups) and adopted a variety of postures, such as lying, sitting, sitting backwards, and facing downwards, to maximize the effect from a horse's movements (Potter, 1993). Furthermore, the temperature of a horse's body is $1^{\circ}$ higher than the human body temperature. This higher temperature and various horse 
GMFM

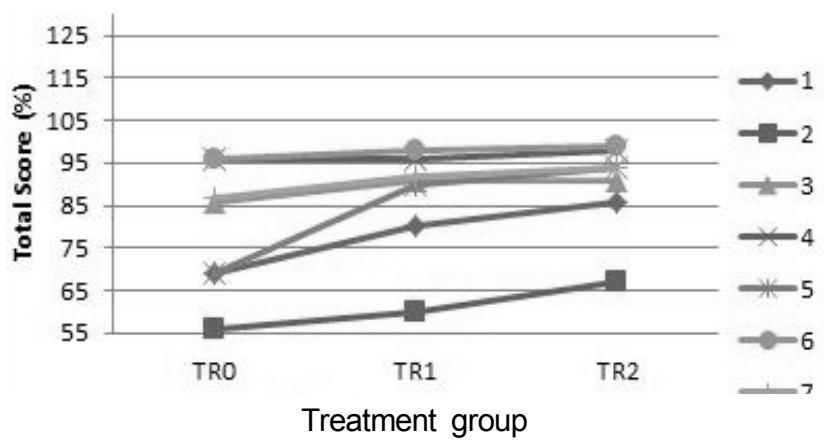

Fig. 2. Changes in GMFM total score (\%) in treatment and control groups.
GMFM

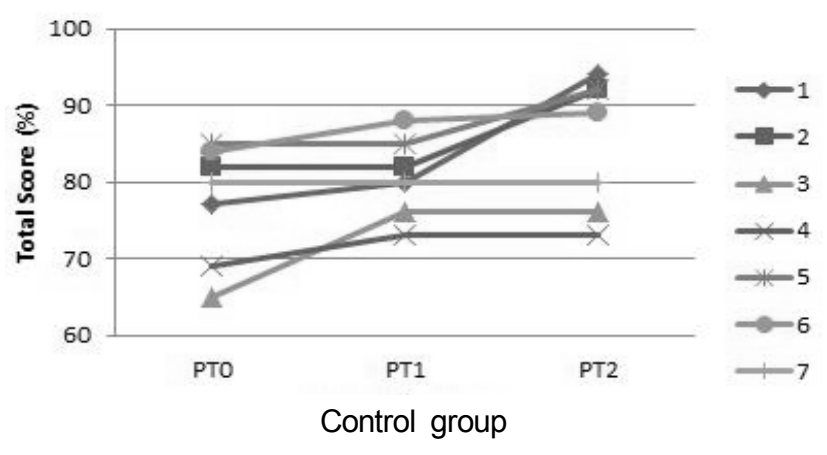

movements reportedly improve the rider's blood circulation and help to relax stiff muscles by reducing abnormally high muscle tone (Sterba et al., 2002).

In this study, a horseback riding program was carried out using a saddle and stirrups. According to NARHA (2002), horseback riding therapy can be categorized by purpose. For example, one purpose may be to improve function by using a horse as a therapeutic tool for the disabled, whereas another purpose may be hippotherapy, or TR, that improves bodily function by teaching horse riding to the disabled.

Therapeutic riding focuses on forming a partnership with the horse. Sitting astride a horse increases balance and coordination, strengthens muscles, and brings about body awareness. Several researchers have reported on the beneficial effects of TR for GMFM in children with spastic cerebral palsy (Steraba et al., 2002; Winchester et al., 2002), but it has been difficult to draw conclusions about the impact of TR on GMFM because MacKinnon et al. (1995) reported no improvements in GMFM in children with CP. Therefore, the effectiveness of horse riding on the disabled was verified in this study by studying the acquisition and practice of horse riding by spastic children. Riders had to keep their balance and maintain control over the horse using various tools as a method of communication, and they were instructed to react to the horse's gait. (conducted with a walk and trot during the TR).

The TR group showed a statistically significant improvement in the percentage score of GMFM dimensions $\mathrm{C}, \mathrm{D}$, and $\mathrm{E}$ $(\mathrm{P}<0.05)$, and the PT group showed significant improvements in GMFM dimensions $\mathrm{B}$ and $\mathrm{E}(\mathrm{P}<0.05)$. Specifically, the $\mathrm{C}, \mathrm{D}$, and $\mathrm{E}$ values for the TR group showed an increase in GMFM dimensions of $6.9 \%, 21 \%$, and $16.6 \%$, respectively, and the PT group showed increases in GMFM B and E values of $1.3 \%$ and $19.7 \%$, respectively. These results appear related to a rider's attempt to repeat 2 beats of standing up from the stirrups and sitting down during horse riding.

Two types of gait used in our study were the walk and the trot. The walk is a 4-beat exercise that adopts a deep-seated position that naturally takes in and absorbs the movement of the horse without straining the rider's muscles in the hipbone, hip, and femoral regions. The second gait of the trot is a 2-beat exercise divided into a rising trot and a sitting trot. The rising trot was used in this study since it involves a rider performing up-and-down movements by stepping on the stirrups and maintaining balance. However, as the riders are disabled, they were instructed to perform up-and-down movements for a certain period of time, even when the gait was a walk. In this process, stimulation appeared to increase through the tendency of riders to put their knees on the horse's body and to rely on their feet in the stirrups while attempting standing and sitting movements.

In a previous study for children with spastic $\mathrm{CP}$, a significant increase in GMFM dimension $\mathrm{E}$ was reported after Sterba et al. (2002) conducted 18 weeks of horse riding with 17 people, and significant improvements were also reported in GMFM dimension E from Chereng et al. (2004) after 16 weeks of horse riding. Furthermore, Kwon et al. (2002) reported noticeable improvements in GMFM dimension $\mathrm{E}$ after 8 weeks of horse riding. However, it is inappropriate to compare overall results in this study with other studies, as there were 12 ambulatory and 5 non-ambulatory participants in the study by Sterba et al. (2002), 6 ambulatory participants and 5 non-ambulatory participants or ambulatory participants with devices in the study by Chereng et al. (2004). In addition, the study by Kwon et al. (2011) was carried out using hippotherapy. 
In horse riding, stirrups generally support the weight of the legs and not the body weight (Kang et al., 2010). However, in this study, instructors let the rider stand and sit (as much as possible with the heel down), thereby repeatedly supporting the body weight on the stirrups. This action is considered to have a positive effect on gross motor function. However, no differences were observed in the ROM and ST tests conducted before and after riding therefore, it was concluded that 16 sessions of horse riding exercise are not effective. Also, assigning importance to the up-and-down movement during the acquisition of horse riding skill was somewhat effective at increasing GMFM, but insufficient for ROM and ST.

According to Bergene (2006), increases in hip ROM at all angles measured were observed over the first 12 weeks with 45 min treatment sessions conducted on a weekly basis for 18 weeks. However, that study was carried out as hippotherapy using a horse as a therapeutic tool and was focused on increasing the rider's stimulation by using a wool pad without resorting to a saddle and stirrups. Thus, future research should be carried out to develop a horse riding program that uses TR to reduce ROM and ST.

This study was limited due to the small number of participants and a wide variety of disabilities; therefore, it was difficult to apply a TR program. As a result, variables that may have acted as potential confounds could not be controlled. In future studies, the number of participants in the TR program must be increased to effectively determine the functional improvements of people with disabilities through TR. Future studies should also develop the TR program to evaluate its treatment effect on other disabilities.

Nevertheless, this study has found that the PT group had improved action skills but that the TR group had more effective improvements than the PT group. Specifically, the $\mathrm{C}, \mathrm{D}$, and $\mathrm{E}$ values for the TR group showed an increase in GMFM dimensions of $6.9 \%, 21 \%$, and $16.6 \%$, respectively, and the PT group showed increases in GMFM dimensions B and $\mathrm{E}$ of $1.3 \%$ and $19.7 \%$, respectively. However, no differences were observed in ROM and ST tests conducted before and after riding therefore, 16 sessions of horse riding exercises were insufficient for revealing effectiveness in these categories. Also, the up-and-down movement during the acquisition of horse riding skills was somewhat effective at increasing GMFM, but insufficient for improving ROM and ST. In conclusion, based on this study, TR is an effective treatment for children with $\mathrm{CP}$.

\section{ACKNOWLEDGEMENTS}

This work was partially supported by a grant from Horse Resources Research Institute. We thank the members of the Ever Spring Rehabilitation Hospital and Jeju Horse Land in Jeju city, Jeju Island, South Korea. Also, we thank the volunteers, participants, and their parents.

\section{REFERENCES}

Baine, A. 1965. Pony riding for the disabled. Physiotherapy, 1: 263-5.

Bergene, M. C. 2006. Therapeutic Horseback Riding in Individuals with Disabilities. Effect on Hip Range of Motion. Senior Research Project, Marian College of Fond du Lac, WI.

Bjornson, K. F., Graubert, C. S., Buford, V. L. and McLaughlin, J. 1998. Validity of the Gross Motor Function Measure. Pediatric Physical Therapy, 10:43-47.

Cherng, R. 2004. The effectiveness of Therapeutic Horseback Riding in Children with Spastic Cerebral Palsy.Adapted Physical Activity Quarterly, 21:103-121.

Dodd, K. J., Taylor, N. J. and Graham, H. K. 2003. A randomized clinical trial of strength training in young people with cerebral palsy. Developmental Medicine and Child Neurology, 45(10):652-657.

Ionatamishvili, N. I. 2004. Riding Therapy as a Method of Rehabilitation of Children with Cerebral Palsy. Human Physiology, 30:561-565.

Kang, O. D., Ryu, Y. C., Ryew, C. C., Oh, W. Y., Lee, C. E. and Kang, M. S. 2010. Comparative analyses of rider position according to skill levels during walk \& trot in Jeju horse. Human Movement Science, 29:956-963.

Kim, H. S., Lee, K W., Hwang, J. H., Kim, E. J, Lee, Y. T., Chung, S. H., Nam, M. S. and Lee, J. Y. 2005. Therapeutic Effects of Horse riding (Hippotherapy) on Motor Development of Children with Cerebral Palsy, Journal Korea Sports Medicine, 23(3):278-283.

Kwon, J. Y., Chang, H. J., Lee, J. Y., Ha, Y. Lee,P. K. and Kim, Y. H. 2011. Effects of hippotherapy on gait parameters in children with bilateral spastic cerebral palsy. Archives Physical Medicine Rehabilitation, 92:774-779.

Lechner, H. 2003. The short-term effect of hippotherapy on spasticity in patients with spinal cord injury. Spinal Cord, 41:502-505.

Lessick, M. 2004. Therapeutic Horseback Riding: Exploring this alternative therapy for women AWHONN Lifelines, 8:46-52. 
Liptak, G. S. 2005. Complementary and alternative therapies for Cerebral Palsy. Mental Retardation and Developmental Disabilities Research Reviews, 11(2):156-163.

MacKinnon, J. 1995. A study of Therapeutic Effects of Horseback riding for children with Cerebral Palsy. Physical \& Occupational therapy in Pediatrics, 15:17-33.

Margaret, M. B., Catherine, A. D. and Maria, M. L. 2009. The Effect of Therapeutic Horseback Riding on Social Functioning in Children with Autism. J Autism Dev Disord, 39:1261-1267.

Matsuura, A., Ohta, E., Ueda, K., Nakatsuji, H. and Kondo, S. 2008. Influence of equine conformation on rider oscillation \& evaluation of horses for therapeutic riding. Journal of equine veterinary science, 19:9-18

NARHA. 2002. National Amercian Riding for the H\&icapped Association Instructor Education Guide. Denver, CO .

Nelson, K. and Russman, B. 2002. "Cerebral Palsy". In K. Swaiman, Pediatric neurology. St Louis: Mosby Inc.

Potter, J. T., Evans, J. W. and Nolt Jr, B. H. 1993. Therapeutic horseback riding. Journal of the American Veterinary Association, 204:131-4.

RDA. 1990. Riding for the Disabled Association: Horses, Ponies \& Donkeys. pp. 43-50. In: The RDA official manual, The Kenilworth Press, London.

Russell, D. J., Rosenbaum, P. L., Gowl, C., Hardy, S., Lane, M., Plews, N., McGavin, H., Cadman, D. and Jarvis, S. 1993. Gross Motor Function Measure Manual. Hamilton, Ontario: Chedoke-McMaster Hospitals \& McMaster University.

Russell, D. J., Rosenbaum, P. L., Cadman, D. T., Gowl, C., Hardy, S. and Jarvis, S. 1989. The gross motor function measure: a means to evaluate the effects of physical therapy. Developmental Medicine \& Child Neurology, 31:341-52.

Sherri, L., Cadenhead, I. R. and David, M. T. 2002. Effect of passive range of motion exercises on lower extremity goniometric measurements of adults with cerebral palsy: A Single-subject Design. Physical Therapy, 82(7):26-37.

Silkwood-Sherer, D. 2007. Effects of hippotherapy on postural stability, in persons with multiple sclerosis: A pilot study, 31: 77-84.

Spink, J. 1993. Developmental Riding Therapy: A Team Approach to Assessment \& Treatment. Tucson, AZ: Therapy Skill Builders.

Sterba, J. A., Rogers, B. T., France, A. P. and Vokes, D. A. 2002. Horseback riding in children with cerebral palsy: effect on gross motor function. Development Med Child Neurology, 44:301-308.

Winchester, P., Kendall, K., Peters, H., Sears, N. and Winkley, T. 2002. The Effect of Therapeutic Horseback Riding on Gross Motor Function \& Gait Speed in Children Who Are Developmentally Delayed, 22:3-4.

Yong, H. C., Kim, C. and Hwang, K. Y. 2010. The Effects of Therapeutic Riding on Activities of Daily Living and Gross Motor Functions of Children with Cerebral Palsy, Journal of Rehabilitation Psychology, 17(3):117-131.

Young, R. 2005. Horsemastership Part 2: Physical, Psychological, Education \& Social Benefits. International Journal of Therapy and Rehabilitation , 12:120-125.

(Received Oct. 31, 2013; Accepted Dec. 23, 2013) 